\title{
Factors associated with maternal mortality at advanced maternal age: a population-based case-control study
}

\author{
SJ McCall, M Nair, M Knight \\ Policy Research Unit in Maternal Health and Care, National Perinatal Epidemiology Unit (NPEU), Nuffield Department of Population Health, \\ University of Oxford, Oxford, UK \\ Correspondence: S McCall, National Perinatal Epidemiology Unit, Nuffield Department of Population Health, University of Oxford, Richard \\ Doll Building, Old Road Campus, Oxford OX3 7LF, UK. Email stephen.mccall@npeu.ox.ac.uk
}

Accepted 17 May 2016. Published Online 13 July 2016.

Objective This study aimed to examine the factors associated with maternal mortality among women aged $\geq 35$ years.

Design Unmatched population based case-control study.

Setting United Kingdom.

Population Between 2009 and 2012, 105 cases of maternal deaths aged $\geq 35$ years were extracted from the surveillance database of the MBRRACE-UK confidential enquiries into maternal deaths in the UK. In addition, 766 controls aged $\geq 35$ years were identified from the UK Obstetric Surveillance System (2005-2012).

Methods Risk factors known to be associated with maternal mortality and morbidity and for which data were available were examined for their association with maternal mortality among women $\geq 35$ years using logistic regression analysis.

Main outcome measures Odds ratios and 95\% confidence intervals associated with maternal death.

Results Five factors were found to be significantly associated with increased odds of death among women aged $\geq 35$ years: smoking during pregnancy (adjusted odds ratio (aOR) 2.06, 95\% CI 1.133.75 ), inadequate use of antenatal care (aOR 23.62, 95\% CI 8.79 63.45), medical co-morbidities (aOR 5.92, 95\% CI 3.56-9.86) and previous pregnancy problems (aOR 2.06, 95\% CI 1.23-3.45). The odds associated with death increased by $12 \%$ per year increase in age (aOR 1.12, 95\% CI 1.02-1.22).

Conclusion Age was associated with maternal mortality even after adjusting for other known risk factors. Importantly, this study showed an association between maternal mortality and smoking among women aged 35 years or older. It emphasises the importance of public health action to reduce smoking levels and address trends in rising maternal age.

Keywords Advanced maternal age, maternal mortality, risk factors, smoking.

Tweetable abstract Smoking is a risk factor for maternal death for those aged over 35 years.

Linked article This article is commented on by ME D'Alton and JM Walsh. To view this mini commentary visit http://dx.doi.org/ 10.1111/1471-0528.14215.

Please cite this paper as: McCall SJ, Nair M, Knight M. Factors associated with maternal mortality at advanced maternal age: a population-based casecontrol study. BJOG 2016; DOI: 10.1111/1471-0528.14216.

\section{Introduction}

A number of global studies have highlighted that the maternal mortality ratio (MMR) increases non-linearly with age, in particular after the age of 30 years, and is highest in the oldest age groups. ${ }^{1,2}$ Although only a small proportion of deaths occur in high income settings, maternal mortality is an increasing concern because of an increase in risk factors such as obesity, ${ }^{3}$ advanced maternal age ${ }^{4}$ and births among migrants. ${ }^{5}$ These factors have been reflected in the increase in maternal deaths in the United States of America (USA) and in the Netherlands. ${ }^{6,7}$
In England and Wales there has been a gradual increase in the proportion of women delivering aged 30 years and older and the average age of childbearing has increased from 26.4 in 1973 to 30.0 in $2013 .^{8}$ As a result, women at an advanced maternal age represent a larger proportion of maternities; data from the Office for National Statistics shows that $20 \%$ of births in England and Wales were to mothers aged 35 years and older in $2013 .^{8}$ This is of concern for several reasons. In particular, older women have an increased prevalence of pre-existing medical co-morbidities. ${ }^{9}$ Women with co-morbidities have been shown to have poorer maternal outcomes during pregnancy. ${ }^{10,11}$ 
However, the low incidence of maternal mortality in high resource countries (10 per 100000 pregnancies per year in the $\mathrm{UK})^{12}$ makes it difficult to investigate the risk factors associated with maternal death in a subgroup of women of older maternal age. Previous literature examining maternal mortality among women of advanced maternal age is therefore limited. The aim of this study, therefore, was to examine the factors associated with maternal mortality among women of advanced maternal age on a national population basis.

\section{Methods}

\section{Study population and design}

This study defined advanced maternal age as women who were aged 35 years or older, therefore the study population comprised of women aged 35 years or older. An unmatched case-control study was conducted using secondary data on maternal deaths occurring between 2009 and 2012 collected through the UK Confidential Enquiry into Maternal Deaths (conducted under the auspices of the Mothers and Babies: Reducing Risk through Audits and Confidential Enquiries across the UK (MBRRACE-UK) collaboration) and data on a nationally representative control group of pregnant women aged 35 years or older collected through the UK Obstetric Surveillance System (UKOSS) between 2005 and 2012 .

All maternal deaths within the UK are prospectively identified through mandatory notification to the MBRRACE-UK collaboration. ${ }^{13}$ The majority of cases are identified by direct notification from death certificates and hospitals; however, other cases are notified through pathologists or coroners and procurators fiscal, midwifery officers, members of the public and inquest reports from the media. ${ }^{12,13}$ Linkage with birth and death registration records from the Office for National Statistics and National Records of Scotland ensures further quality assurance and case ascertainment. ${ }^{12,13}$ Anonymised clinical and demographic data were extracted from the case notes for each maternal death.

In brief, UKOSS is a national surveillance system that enables the study of rare complications in pregnancy. ${ }^{14}$ Case notification cards are returned monthly from consultant-led maternity centres in the UK. In many UKOSS studies, units are asked to return clinical and demographic data on a representative sample of women lacking the specific condition under study (control women). Controls are identified as the two women delivering prior to the woman with the relevant condition under study (case) from a specific obstetric unit. For the purposes of this study, information on all control pregnant women aged 35 and over were extracted from the UKOSS database.
The primary outcome for this study was maternal death: cases were defined as maternal deaths in women aged $\geq 35$ years and controls were population-level UKOSS controls aged $\geq 35$ years. Exposure variables were selected $a$ priori guided by the findings of a literature review. The exposure variables explored in the analysis were age, ethnicity, BMI, marital status, substance misuse, smoking status during pregnancy, previous pregnancy problems, preexisting medical problems (further information in Supporting Information Appendix S1), gestational diabetes, previous fetal loss or termination, parity, multiple pregnancy and inadequate use of antenatal care. Continuous variables were tested for departure from linearity. Baseline groups were chosen using standard reference groups, guided by previous literature or the group with the lowest risk of maternal mortality if no standard reference was available.

Previous UKOSS studies have shown that the distribution of missing data across variables is not random; ${ }^{15}$ for this reason, multiple imputation was considered inappropriate. Thus, to account for missing data, a separate 'missing' category was created for each variable with missing data. Sensitivity analyses were undertaken to examine further the impact of missing data by regrouping women with missing information into the extreme categories of the variables; in addition, complete case analysis was also conducted to assess the impact of including a proxy variable.

The cases were the total number of maternal deaths among women aged $\geq 35$ years in the UK between 2009 and $2012,{ }^{12}$ therefore the study population of 105 for the cases was fixed. From the total number of population-based controls in the UKOSS database, 766 were aged 35 years or older, thereby fixing the sample size for the controls. This number of cases and controls gives an estimated study power of $80 \%$ at the $5 \%$ significance level to detect minimum odds ratios of 2.65 and 1.90 for 5 and $20 \%$ prevalences of exposures in the control group, respectively.

\section{Statistical analysis}

Univariable unconditional logistic regression analysis was conducted to compare the prevalence of the exposure variables in the cases and the controls. Odds ratios with $95 \%$ confidence intervals were calculated. Collinearity was assessed between all plausible linear associations prior to multivariable analysis, using Pearson's correlation coefficient. Substance misuse was highly correlated with previous pregnancy problems (coefficient $=0.436$ ); thus, substance misuse was excluded from the multivariable analysis. No other independent variables were found to be significantly co-linear. Plausible interactions were tested between preexisting mental health problems and inadequate use of antenatal care; smoking status and socio-economic group; smoking and pre-existing medical conditions; smoking and pre-existing hypertension; ethnicity and socio-economic 
group; pre-existing medical conditions and inadequate use of antenatal care; gestational diabetes and BMI. No significant interactions were found.

We specified a priori that a forward stepwise regression method would be used to select covariates; this was deemed appropriate for an exploratory analysis with a restricted number of cases; ${ }^{16}$ a $P$-value $<0.05$ at the univariable level was chosen as a cut-off for including variables in the multivariable model. Each potential exposure variable was included if it was associated with the outcome $(P$-value for Wald test $<0.05$ ) and significantly improved the model fit assessed by likelihood ratio tests at the $5 \%$ significance level. The final model (Model A) included five risk factors that were significantly associated with maternal mortality.

A further exploratory analysis examined the relationship of individual pre-existing medical conditions with maternal mortality. Guided by previous literature, the association between 12 co-morbidities and the outcome was assessed in univariable models. A multivariable analysis was undertaken if a co-morbidity was found to be significant at the univariable level.

Two sensitivity analyses were conducted. The first used complete case analysis for the final multivariable logistic regression (Model B). The second sensitivity analysis restricted the UKOSS controls to women who had their pregnancy during 2009-2012 to match with the time-period of death of the included cases (Model C).

A cumulative 'risk score' was created to assess the odds of maternal death associated with more than one factor. These factors were those that were found to be significantly associated with maternal death during the multivariable analysis. Employing the method used by Kayem et al. ${ }^{17}$ a score of one was assigned for each risk factor. ${ }^{11,17}$ The score was treated as a categorical variable with 'no risk factors' as the baseline group. The additive effect of the presence of one or more risk factors was examined in a separate univariable regression model. All analyses were completed using STATA V.13 (StataCorp, College Station, TX, USA).

\section{Results}

The MBRRACE-UK confidential enquiry identified 105 maternal deaths among women aged 35 years or older. Data were available on 766 control women aged 35 years or older from the UKOSS database.

Table 1 presents the characteristics of cases and controls. Marital status, multiple pregnancy and parity were not statistically significantly associated with maternal death and therefore were not examined in the multivariable analysis.

Table 2 shows the results of the multivariable logistic regression analysis. Five variables, were significantly associated with maternal mortality among women of advanced maternal age. The odds of maternal death were two times higher among women who smoked during pregnancy than among those who did not. The presence of pre-existing medical problems was associated with almost a 6-fold increase in the odds of maternal mortality and the presence of pregnancy problems was associated with a two-fold increase in the odds of death. The odds of death were 23 times higher for those with inadequate use of antenatal care than those with adequate use of antenatal care. The adjusted odds of maternal mortality increased by $12 \%$ per year increase in age (aOR 1.12, 95\% CI 1.02-1.22).

The sensitivity analyses shown in Models B (complete case analysis) and C (restricting the controls to 2009-2012 to match with the time-period for the cases) did not materially change the results. However, the reduced sample size in model $\mathrm{C}$ resulted in age and smoking becoming statistically non-significant at $P<0.05$; nevertheless, the magnitude of the odds ratio remained similar to Models A and $\mathrm{B}$.

The results of the exploratory analysis examining the association of specific medical co-morbidities with maternal mortality are shown in Table 3 . The number of women who had each condition was small, so the results must be interpreted with caution. After adjustment, compared with the controls, women who died had significantly higher odds of cardiac disease, essential hypertension, musculoskeletal disorders, inflammatory conditions, neurological conditions, asthma, mental health problems and infection.

Table 4 shows the association between the cumulative risk score and maternal mortality among women of advanced maternal age. The odds of maternal death increased with the number of risk factors possessed. Presence of one risk factor was associated with an almost threefold increased odds of death, which increased to 12 times for the presence of two risk factors and 26 times increased odds of maternal death for the presence of three risk factors.

\section{Discussion}

\section{Main findings}

This study found five factors to be associated with increased likelihood of maternal mortality among women aged 35 years or older: smoking during pregnancy, older maternal age, pre-existing medical comorbidities, previous pregnancy problems and inadequate use of antenatal care. An exploratory analysis examining medical co-morbidities highlighted that cardiac disease, essential hypertension, infection, musculoskeletal disorders, asthma, mental health disorders, inflammatory disorders and neurological disorders were all independently associated with maternal mortality in women of advanced maternal age. 
McCall et al.

Table 1. Characteristics of cases and controls at advanced maternal age in the UK

\begin{tabular}{|c|c|c|c|c|}
\hline Characteristic & $\begin{array}{l}\text { Number }(\%) \text { of } \\
\text { cases }(n=105)\end{array}$ & $\begin{array}{c}\text { Number }(\%)^{*} \text { of } \\
\text { comparison women }(n=766)\end{array}$ & $\begin{array}{l}\text { Unadjusted odds ratios } \\
\text { (95\% Confidence intervals) }\end{array}$ & $P$-value \\
\hline \multicolumn{5}{|l|}{ Socio-demographic characteristics } \\
\hline \multicolumn{5}{|l|}{ Age* $^{*}$} \\
\hline Median (IQR) & $38(36-40)$ & $37(35-39)$ & $1.10(1.02-1.19)$ & 0.014 \\
\hline \multicolumn{5}{|l|}{ Ethnic group } \\
\hline White & $75(71.4)$ & $620(80.9)$ & 1 & \\
\hline Black or other minority ethnic groups & $28(26.7)$ & $132(17.2)$ & $1.75(1.09-2.81)$ & 0.020 \\
\hline Missing & $2(1.9)$ & $14(1.8)$ & $1.18(0.26-5.30)$ & 0.828 \\
\hline \multicolumn{5}{|l|}{ Marital status } \\
\hline Single & $9(8.6)$ & $52(6.8)$ & $1.42(0.67-3.02)$ & 0.362 \\
\hline Married & $64(61.0)$ & $525(68.5)$ & 1 & \\
\hline Cohabiting & $30(28.6)$ & $183(23.9)$ & $1.34(0.84-2.14)$ & 0.212 \\
\hline Missing & $2(1.9)$ & $6(0.8)$ & $2.73(0.54-13.83)$ & 0.224 \\
\hline \multicolumn{5}{|l|}{ Socio-economic group } \\
\hline Employed & $75(71.4)$ & $619(80.8)$ & 1 & \\
\hline Unemployed & $10(9.5)$ & $33(4.3)$ & $2.50(1.18-5.28)$ & 0.016 \\
\hline Missing & $20(19.0)$ & $114(14.9)$ & $1.45(0.85-2.47)$ & 0.173 \\
\hline \multicolumn{5}{|l|}{$\mathrm{BMI}, \mathrm{kg} / \mathrm{m}^{2}$} \\
\hline$<18.5-24.9$ & $41(39.0)$ & $326(42.6)$ & 1 & \\
\hline $25.0-29.9$ & $16(15.2)$ & $209(27.3)$ & $0.61(0.33-1.11)$ & 0.107 \\
\hline$>30$ & $36(34.3)$ & $149(19.5)$ & $1.92(1.18-3.13)$ & 0.009 \\
\hline Missing & $12(11.4)$ & $82(10.7)$ & $1.16(0.59-2.31)$ & 0.666 \\
\hline \multicolumn{5}{|l|}{ Smoking status } \\
\hline Never/ex-smoker & $68(64.8)$ & $659(86.0)$ & 1 & \\
\hline Smoked during pregnancy & $25(23.8)$ & $96(12.5)$ & $2.52(1.52-4.19)$ & $<0.001$ \\
\hline Missing & $12(11.4)$ & $11(1.4)$ & $10.57(4.49-24.87)$ & $<0.001$ \\
\hline \multicolumn{5}{|l|}{ Substance misuse } \\
\hline No & $97(92.4)$ & $749(97.8)$ & 1 & \\
\hline Yes & $7(6.7)$ & $1(0.1)$ & $54.05(6.58-444.02)$ & $<0.001$ \\
\hline Missing & $1(1.0)$ & $16(2.1)$ & $0.48(0.06-3.68)$ & 0.482 \\
\hline \multicolumn{5}{|l|}{ Previous medical history } \\
\hline \multicolumn{5}{|l|}{ Previous or pre-existing medical condition } \\
\hline None & $41(39.0)$ & $600(78.3)$ & 1 & \\
\hline Yes & $60(57.1)$ & $118(15.4)$ & $7.44(4.78-11.59)$ & $<0.001$ \\
\hline Missing & $4(3.8)$ & $48(6.3)$ & $1.22(0.42-3.55)$ & 0.716 \\
\hline \multicolumn{5}{|l|}{ Previous pregnancy problems** } \\
\hline None & $50(47.6)$ & $581(75.8)$ & 1 & \\
\hline Yes & $49(46.7)$ & $181(23.6)$ & $3.15(2.05-4.83)$ & $<0.001$ \\
\hline Missing & $6(5.7)$ & $4(0.5)$ & $17.43(4.76-63.81)$ & $<0.001$ \\
\hline \multicolumn{5}{|l|}{ Pregnancy-related characteristics } \\
\hline \multicolumn{5}{|l|}{ Gestational diabetes } \\
\hline No & $88(83.8)$ & $737(96.2)$ & 1 & \\
\hline Yes & $9(8.6)$ & $28(3.7)$ & $2.69(1.23-5.89)$ & 0.013 \\
\hline Missing & $8(7.6)$ & $1(0.1)$ & $67.00(8.28-542.01)$ & $<0.001$ \\
\hline \multicolumn{5}{|l|}{ Previous fetal loss or termination } \\
\hline 0 & $49(46.7)$ & $468(61.1)$ & 1 & \\
\hline 1 or more & $51(48.6)$ & $293(38.3)$ & $1.66(1.09-2.53)$ & 0.017 \\
\hline Missing & $5(4.8)$ & $5(0.7)$ & $9.55(2.67-34.15)$ & 0.001 \\
\hline \multicolumn{5}{|l|}{ Multiple pregnancy } \\
\hline No & $99(94.3)$ & $754(98.4)$ & 1 & \\
\hline Yes & $4(3.8)$ & $12(1.6)$ & $2.54(0.80-8.02)$ & 0.113 \\
\hline Missing & $2(1.9)$ & $0(0.0)$ & Omitted & \\
\hline \multicolumn{5}{|l|}{ Inadequate use of antenatal care*** } \\
\hline No & $80(76.2)$ & $756(98.7)$ & 1 & \\
\hline
\end{tabular}


Table 1. (Continued)

\begin{tabular}{|c|c|c|c|c|}
\hline Characteristic & $\begin{array}{l}\text { Number }(\%) \text { of } \\
\text { cases }(n=105)\end{array}$ & $\begin{array}{c}\text { Number }(\%)^{*} \text { of } \\
\text { comparison women }(n=766)\end{array}$ & $\begin{array}{l}\text { Unadjusted odds ratios } \\
\text { (95\% Confidence intervals) }\end{array}$ & $P$-value \\
\hline Yes & $25(23.8)$ & $9(1.2)$ & $26.25(11.84-58.19)$ & $<0.001$ \\
\hline Missing & $0(0.0)$ & $1(0.1)$ & Omitted & \\
\hline \multicolumn{5}{|l|}{ Parity } \\
\hline Nulliparous & $22(21)$ & $208(27.2)$ & 1 & \\
\hline Multiparous & $82(78.1)$ & $558(72.8)$ & $1.39(0.85-2.28)$ & 0.194 \\
\hline Missing & $1(1.0)$ & $0(0.0)$ & Omitted & \\
\hline
\end{tabular}

BMI, body mass index; IQR, interquartile range.

* No missing observations.

**Previous pregnancy problems included a history of a number of conditions in one or more previous pregnancies such as gestational diabetes, hypertensive disorder of pregnancy, thrombotic events, placental problems, infection, haemorrhage and puerperal psychosis.

$* * *$ Inadequate use of antenatal care indicated that the woman was late in registering their pregnancy, concealed their pregnancy, missed antenatal appointments or did not attend any appointments.

Table 2. Adjusted analysis examining factors associated with maternal death at advanced maternal age

\begin{tabular}{|c|c|c|c|c|c|c|}
\hline \multirow[t]{2}{*}{ Characteristic } & \multicolumn{2}{|c|}{ Model A $(n=870)^{*}$} & \multicolumn{2}{|c|}{ Model B $(n=798)^{* *}$} & \multicolumn{2}{|c|}{ Model C $(n=369)^{* * *}$} \\
\hline & $\begin{array}{l}\text { Adjusted OR } \\
(95 \% \mathrm{Cl})\end{array}$ & $P$-value & $\begin{array}{l}\text { Adjusted OR } \\
(95 \% \mathrm{Cl})\end{array}$ & $P$-value & $\begin{array}{l}\text { Adjusted OR } \\
(95 \% \mathrm{Cl})\end{array}$ & $P$-value \\
\hline \multicolumn{7}{|c|}{ Socio-demographic characteristics } \\
\hline $\operatorname{Age}^{\star \star \star \star}$ & $1.12(1.02-1.22)$ & 0.013 & $1.11(1.01-1.21)$ & 0.025 & $1.05(0.95-1.16)$ & 0.326 \\
\hline \multicolumn{7}{|l|}{ Smoking status } \\
\hline Never/ex-smoker & 1 & & 1 & & 1 & \\
\hline Smoked during pregnancy & $2.06(1.13-3.75)$ & 0.019 & $2.04(1.12-3.74)$ & 0.020 & $2.03(0.99-4.14)$ & 0.052 \\
\hline Missing & $5.69(1.54-20.98)$ & 0.009 & & & $7.04(0.96-51.76)$ & 0.055 \\
\hline \multicolumn{7}{|l|}{ Previous medical history } \\
\hline \multicolumn{7}{|l|}{ Pre-existing medical conditions } \\
\hline None & 1 & & 1 & & 1 & \\
\hline Yes & $5.92(3.56-9.86)$ & $<0.001$ & $5.50(3.30-9.16)$ & $<0.001$ & $4.44(2.48-7.94)$ & $<0.001$ \\
\hline Missing & $0.27(0.05-1.43)$ & 0.124 & & & $1.22(0.08-19.61)$ & 0.888 \\
\hline \multicolumn{7}{|l|}{ Previous pregnancy problems } \\
\hline No & 1 & & 1 & & 1 & \\
\hline Yes & $2.06(1.23-3.45)$ & 0.006 & $2.03(1.20-3.41)$ & 0.008 & $1.98(1.09-3.61)$ & 0.025 \\
\hline Missing & $3.49(0.39-30.95)$ & 0.262 & & & $0.79(0.06-11.02)$ & 0.864 \\
\hline \multicolumn{7}{|c|}{ Pregnancy-related characteristics } \\
\hline \multicolumn{7}{|c|}{ Inadequate use of antenatal care } \\
\hline No & 1 & & 1 & & 1 & \\
\hline Yes & $23.62(8.79-63.45)$ & $<0.001$ & $15.75(5.58-44.50)$ & $<0.001$ & $19.92(4.95-80.20)$ & $<0.001$ \\
\hline Missing & Omitted $* * * * *$ & & Omitted $* * * * *$ & & Omitted $* * * * *$ & \\
\hline
\end{tabular}

95\% Cl, 95\% confidence intervals; OR, odds ratios.

Each model adjusted for the five variables shown in the table.

* Model A: main model using proxy variables for missing data.

** Model B: sensitivity analysis: using complete case analysis.

***Model C: sensitivity analysis: using UKOSS controls restricted to women delivering between 2009 and 2012.

$* * * *$ No missing observations.

$* * * * *$ Omitted as no missing values in cases.

\section{Strengths and limitations}

The use of a highly robust national surveillance system and the collection of cases over 4 years has enabled the examination of this subset of maternal mortalities in a high resource setting and thus overcomes some of the limitations of previous research. Both prospective population- 
McCall et al.

Table 3. Exploratory analysis examining pre-existing medical conditions associated with maternal mortality at advanced maternal age

\begin{tabular}{|c|c|c|c|c|}
\hline Characteristic & Number $(\%)$ of cases & Number $(\%)$ of controls & Unadjusted OR (95\% Cl) & Adjusted* OR $(95 \% \mathrm{Cl})$ \\
\hline \multicolumn{5}{|l|}{ Cardiac disease } \\
\hline No & $94(93.1)$ & $710(98.9)$ & 1 & 1 \\
\hline Yes & $7(6.9)$ & $8(1.1)$ & $6.61(2.34-18.64)$ & $9.98(3.29-30.23)$ \\
\hline \multicolumn{5}{|c|}{ Pre-existing diabetes mellitus (Type $1 \& 2$ ) } \\
\hline No & $97(96.0)$ & $714(99.4)$ & 1 & 1 \\
\hline Yes & $4(4.0)$ & $4(0.6)$ & $7.36(1.81-29.91)$ & $5.04(0.86-29.61)$ \\
\hline \multicolumn{5}{|c|}{ Essential hypertension } \\
\hline No & $92(91.1)$ & $711(99)$ & 1 & 1 \\
\hline Yes & $9(8.9)$ & $7(1.0)$ & $9.94(3.61-27.32)$ & $6.44(2.14-19.35)$ \\
\hline \multicolumn{5}{|c|}{ Haematological disorders } \\
\hline No & $92(91.1)$ & $704(98.1)$ & 1 & 1 \\
\hline Yes & $9(8.9)$ & $14(1.9)$ & $4.92(2.07-11.68)$ & $2.48(0.87-7.09)$ \\
\hline \multicolumn{5}{|c|}{ Prior thrombotic event } \\
\hline No & $98(97.0)$ & 715 (99.6) & 1 & 1 \\
\hline Yes & $3(3.0)$ & $3(0.4)$ & $7.30(1.45-36.65)$ & $3.28(0.42-25.72)$ \\
\hline \multicolumn{5}{|c|}{ Inflammatory conditions } \\
\hline No & $82(81.2)$ & $716(99.7)$ & 1 & 1 \\
\hline Yes & $19(18.8)$ & $2(0.3)$ & $82.95(18.98-362.52)$ & 65.05 (14.28-296.37) \\
\hline \multicolumn{5}{|c|}{ Musculoskeletal disorders } \\
\hline No & $92(91.1)$ & 717 (99.9) & 1 & 1 \\
\hline Yes & $9(8.9)$ & $1(0.1)$ & $70.14(8.79-559.96)$ & $63.10(7.48-532.36)$ \\
\hline \multicolumn{5}{|l|}{ Asthma } \\
\hline No & $92(91.1)$ & $692(96.4)$ & 1 & 1 \\
\hline Yes & $9(8.9)$ & $26(3.6)$ & $2.60(1.18-5.73)$ & $2.72(1.14-6.46)$ \\
\hline \multicolumn{5}{|l|}{ Epilepsy } \\
\hline No & $100(99)$ & $714(99.4)$ & 1 & \\
\hline Yes & $1(1)$ & $4(0.6)$ & $1.79(0.20-16.13)$ & Excluded \\
\hline \multicolumn{5}{|c|}{ Mental health problems } \\
\hline No & $83(82.2)$ & $689(96)$ & 1 & 1 \\
\hline Yes & $18(17.8)$ & $29(4)$ & $5.15(2.74-9.68)$ & $3.27(1.53-7.01)$ \\
\hline \multicolumn{5}{|c|}{ Neurological conditions } \\
\hline No & $95(94.1)$ & 717 (99.9) & 1 & 1 \\
\hline Yes & $6(5.9)$ & $1(0.1)$ & $45.28(5.39-380.22)$ & $17.84(1.80-177.12)$ \\
\hline \multicolumn{5}{|l|}{ Infection } \\
\hline No & $93(92.1)$ & 713 (99.3) & 1 & 1 \\
\hline Yes & $8(7.9)$ & $5(0.7)$ & $12.27(3.93-38.28)$ & $11.49(3.26-40.47)$ \\
\hline
\end{tabular}

$95 \% \mathrm{Cl}, 95 \%$ confidence intervals; OR, odds ratio.

Missing data in pre-existing medical problem, $n=52$.

See Appendix $\mathrm{S} 1$ for more information on included conditions.

Each pre-existing medical problem was modelled separately in the main model using complete case analysis.

*Adjusted for age, smoking status, previous pregnancy problem and inadequate use of antenatal care.

based surveillance systems use a robust methodology, which reduces any possible impact of selection bias. The cases were the total number of maternal deaths in the UK among women aged 35 years or older. The UKOSS controls may have been higher risk pregnancies, as they are drawn from consultant-led maternity units. As a result, they may have higher complication rates, which may bias our effect estimates towards the null in comparison with a truly representative pregnancy population. This dataset included controls from all but the very smallest consultant maternity units in the UK and thus can be considered nationally representative of the population of women delivering in hospitals with consultant units. The use of national data allowed a valid comparison between the cases and the controls, as they were drawn from the same population.

However, the data collection process was not blinded and so may have been susceptible to information bias. Additionally the number of cases were still small, which limited the study power, particularly when investigating rarer exposures.

There were some missing data, notably concerning socio-economic status, BMI and smoking status. Missing data impacted the size of the model when complete case 
Table 4. Cumulative risk score for specified factors

\begin{tabular}{lcccr}
\hline $\begin{array}{l}\text { Number } \\
\text { of factors }\end{array}$ & $\begin{array}{c}\text { Cases, } \\
\boldsymbol{n}(\%)\end{array}$ & $\begin{array}{c}\text { Controls, } \\
\boldsymbol{n}(\%)\end{array}$ & uOR & $\mathbf{9 5 \% ~ C l}$ \\
\hline 0 & $14(13.3)$ & $366(49.7)$ & 1 & \\
1 & $28(26.7)$ & $263(35.7)$ & 2.78 & $(1.43-5.39)$ \\
2 & $42(40.0)$ & $92(12.5)$ & 11.93 & $(6.25-22.78)$ \\
3 & $16(15.2)$ & $16(2.2)$ & 26.14 & $(10.90-62.69)$ \\
4 & $5(4.8)$ & $0(0.0)$ & Not calculated* & \\
\hline
\end{tabular}

Risk factors included: age as a binary variable $(35-40,>40)$, preexisting medical problems, previous pregnancy problems, smoking during pregnancy and inadequate use of antenatal care. * Not calculated, as there were no controls with four risk factors.

analysis was undertaken; however, the results did not vary substantially to that of the model with missing data included as a proxy value.

The employment variable included in this study is unlikely to capture fully the complexity of socio-economic status. Studies have shown that socio-economic status could be associated with antenatal care $^{18}$; however, we did not find any significant moderate to strong correlation between employment status and antenatal care.

\section{Interpretation}

Previous studies have not reported any significant association between smoking and maternal mortality. ${ }^{11,17,19}$ However, studies examining maternal morbidities have shown that smoking could have a protective effect against a number of maternal morbidities such as haemorrhage ${ }^{20}$ and preeclampsia. ${ }^{20,21}$ The protective effect against individual morbidities does not imply smoking would be protective against mortality. This result may be explained by the duration of smoking, as the deleterious effects of smoking may take many years to manifest themselves. Previous research has shown that the risk of cardiovascular events increases with duration of smoking. ${ }^{22}$ We do not have information on the duration of smoking in each woman; however, age and length of smoking have been shown to be collinear, with the majority of smokers starting in adolescence. ${ }^{22}$ Therefore, the impact of smoking on pregnancy risk may only present in older women. This would explain the null findings in previous studies which examined maternal mortality in all ages. ${ }^{11,17}$ Nonetheless, the association between smoking and maternal mortality could also be an artefact as a result of information bias; the reporting of information for the cases may be more accurate than the reporting for the controls. However, more cases did not have information about smoking status than the controls. Results of a sensitivity analysis conducted by re-grouping women with missing information into smoking and non-smoking groups did not differ materially from the findings of the main model.
Interestingly, even after adjusting for known risk factors, the association between age and mortality was not attenuated. The literature has previously suggested that the association between age and maternal mortality can be fully explained by medical comorbidities. ${ }^{9}$ One possible explanation being that older women undergo cardiovascular ageing and older women are more likely to have symptoms of an underlying undiagnosed cardiovascular condition that results in an inability to adapt to the normal physiological changes that occur during pregnancy. ${ }^{9}$ Thus, the weakened vascular system in older women is unable to compensate fully for the physiological demands that occur during pregnancy, which in turn increases the risk of cardiovascular events, pregnancy-induced hypertension and other complications. $^{23}$

Inadequate antenatal care was the strongest association found in this study and this finding was similar to previous published studies. ${ }^{11,19}$ It is likely that this relationship may be partially explained by socio-economic status ${ }^{18}$ and immigration status, ${ }^{24}$ which were either not fully adjusted for or not available in this study.

Similar to previously published studies, older women with pre-existing medical conditions were independently at an increased risk of maternal mortality. ${ }^{11} \mathrm{~A}$ number of studies have shown that medical co-morbidities such as hypertension, ${ }^{9}$ cardiac disease, ${ }^{25}$ asthma, ${ }^{26}$ inflammatory disease, ${ }^{11}$ mental health problems, ${ }^{27}$ infection, ${ }^{9}$ musculoskeletal disorders ${ }^{11}$ and neurological conditions ${ }^{11}$ were associated with maternal morbidity and mortality. In contrast to some previous literature this study did not find an association between obesity and maternal mortality. ${ }^{17}$ Obesity has been shown to be associated with maternal complications in older women. ${ }^{28}$ This highlights once again the importance of high quality pre-pregnancy as well as antenatal and post-pregnancy care for women with co-morbidities, ${ }^{12}$ particularly among older women.

Similar to previous research, this study highlighted that there was an association between previous pregnancy problems and maternal mortality. ${ }^{11}$ Many of these problems are associated with an increased risk of complications in subsequent pregnancies; for example, previous histories of preeclampsia and postpartum haemorrhage have been shown to be associated with future morbidity..$^{20,29,30}$ It has been suggested that inter-pregnancy care targeted at the management of hypertension and diabetes could improve future pregnancy outcomes. ${ }^{31}$ However, research evaluating the impact on future outcome is lacking.

\section{Conclusions}

This study identified five risk factors associated with maternal mortality in women of advanced maternal age. After adjusting for other known risk factors, older age remained 
associated with maternal mortality. This result suggests there are other unmeasured factors that are responsible for this association. Importantly, this study showed an association between maternal mortality and smoking among women aged 35 years or older, which may be due to a more lengthy smoking exposure than in younger women. The study emphasises that modifying factors such as smoking and antenatal care access could prevent deaths in this age group. Further research is needed to investigate the social factors associated with older maternal age at childbearing and possible reversal of this trend. Medical comorbidities were an important risk factor for maternal mortality among women of advanced maternal age, which in turn emphasises the importance or pre-pregnancy care, as well as multidisciplinary antenatal and post-pregnancy care. Further research is needed to identify other factors underlying the maternal mortality risk among older women.

\section{Disclosure of interests}

None declared. Completed disclosure of interests form available to view online as supporting information.

\section{Contribution to authorship}

SJM analysed and interpreted the data and wrote the first draft of the paper. MN extracted the data, supervised the data analysis and assisted with the writing of the paper. MK designed the study, supervised the analysis and assisted with the writing of the paper.

\section{Details of ethics approval}

Permission for the secondary use of anonymised data from MBRRACE was sought from the Healthcare Quality Improvement Partnership (HQIP). Each study had obtained its required approvals for the primary collection of data. UKOSS gained ethical approval from the London Multicentre Research Ethics Committee (study reference 04/MRE02/45). In England and Wales, MBRRACE-UK has approval from the Secretary of State for Health, attained by request to the Confidentiality Advisory Group of the Health Research Authority (it was formally known as National Information Governance Board) (ECC 5-05 (f)/ 2012). ${ }^{13}$ Permissions were gained from the respective bodies within Scotland and Northern Ireland.

\section{Funding}

This paper reports on an independent study which is partfunded by the Policy Research programme in the Department of Health. This work formed part of SJM's Masters of Science in Global Health Science, which was funded by the Nuffield Department of Population Health, University of Oxford. MK is funded by an NIHR Research Professorship. The Maternal, Newborn and Infant Clinical Outcome
Review programme, delivered by MBRRACE-UK, is commissioned by the Healthcare Quality Improvement Partnership (HQIP) on behalf of NHS England, NHS Wales, the Health and Social care division of the Scottish Government, the Northern Ireland Department of Health, Social Services and Public Safety (DHSSPS), the States of Jersey, Guernsey, and the Isle of Man. The views expressed in this publication are those of the author(s) and not necessarily those of the NHS, HQIP, the NIHR, or the Department of Health. The funders had no role in the study design, data collection and analysis, decision to publish, or preparation of the article.

\section{Acknowledgements}

None.

\section{Supporting Information}

Additional Supporting Information may be found in the online version of this article:

Appendix S1. Included conditions.

\section{References}

1 Kassebaum NJ, Bertozzi-Villa A, Coggeshall MS, Shackelford KA, Steiner $C$, Heuton KR, et al. Global, regional, and national levels and causes of maternal mortality during 1990-2013: a systematic analysis for the Global Burden of Disease Study 2013. Lancet 2014;384:980-1004.

2 Blanc AK, Winfrey W, Ross J. New findings for maternal mortality age patterns: aggregated results for 38 countries. PLOS ONE 2013;8: e59864.

3 Heslehurst N, Rankin J, Wilkinson JR, Summerbell CD. A nationally representative study of maternal obesity in England, UK: trends in incidence and demographic inequalities in 619323 births, 19892007. Int J Obes 2010;34:420-8.

4 WHO/Europe. European Health for All database (HFA-DB). 2014 [http://data.euro.who.int/hfadb/linecharts/linechart.php? $\mathrm{W}=1920 \& \mathrm{~h}=1080]$. Accessed 2 June 2015.

5 Tromans N, Natamba E, Jefferies J. Have Women Born Outside the UK Driven the Rise in UK Births Since 2001? London: Office for National Statistics, 2007.

6 Berg CJ, Callaghan WM, Syverson C, Henderson Z. Pregnancyrelated mortality in the United States, 1998 to 2005. Obstet Gynecol 2010;116:1302-9.

7 Schutte JM, Steegers EAP, Schuitemaker NWE, Santema JG, De Boer $\mathrm{K}$, Pel $\mathrm{M}$, et al. Rise in maternal mortality in the Netherlands. BJOG 2010;117:399-406.

8 Office for National Statistics. Live Births In England and Wales by Characteristics of Mother 1, 2013. London: Office for National Statistics, 2013.

9 van Katwijk C, Peeters LL. Clinical aspects of pregnancy after the age of 35 years: a review of the literature. Hum Reprod Update 1998;4:185-94.

10 Carolan M. The graying of the obstetric population: implications for the older mother. J Obstet Gynecol Neonatal Nurs 2003;32:19-27.

11 Nair M, Kurinczuk JJ, Brocklehurst P, Sellers S, Lewis G, Knight M. Factors associated with maternal death from direct pregnancy complications: a UK national case-control study. BJOG 2014:122:653-62. 
12 Knight M, Kenyon S, Brocklehurst P, Neilson J, Shakespeare J, Kurinczuk J, et al. Saving Lives, Improving Mothers' Care: lessons learned to inform future maternity care from the UK and Ireland confidential enquiries into maternal deaths and Morbidity 2009-2012. Oxford: National Perinatal Epidemiology Unit, University of Oxford, 2014

13 Kurinczuk JJ, Draper ES, Field DJ, Bevan C, Brocklehurst P, Gray R, et al. Experiences with maternal and perinatal death reviews in the UK-the MBRRACE-UK programme. BJOG 2014;121:41-6.

14 Knight M, Kurinczuk JJ, Tuffnell D, Brocklehurst P. The UK obstetric surveillance system for rare disorders of pregnancy. BJOG 2005;112:263-5.

15 Lindquist A, Knight M, Kurinczuk JJ. Variation in severe maternal morbidity according to socioeconomic position: a UK national casecontrol study. BMJ Open 2013;3:pii: e002742.

16 Wittink DR. The Application of Regression Analysis. Boston: Allyn \& Bacon, 1988.

17 Kayem G, Kurinczuk J, Lewis G, Golightly S, Brocklehurst P, Knight M. Risk factors for progression from severe maternal morbidity to death: a national cohort study. PLOS ONE 2011;6:e29077.

18 Rowe RE, Garcia J. Social class, ethnicity and attendance for antenatal care in the United Kingdom: a systematic review. J Public Health 2003;25:113-9.

19 Nair M, Knight M, Kurinczuk J. Risk factors and newborn outcomes associated with maternal deaths in the UK from 2009 to 2013: a national case-control study. BJOG doi: 10.1111/1471-0528.13978. [Epub ahead of print]

20 Waterstone M, Wolfe C, Bewley S. Incidence and predictors of severe obstetric morbidity: case-control study. Br Med J 2001;322:1089-93.

21 Cnattingius S, Mills JL, Yuen J, Eriksson O, Ros HS. The paradoxical effect of smoking in preeclamptic pregnancies: smoking reduces the incidence but increases the rates of perinatal mortality, abruptio placentae, and intrauterine growth restriction. Am J Obstet Gynecol 1997;177:156-61.
22 Centers for Disease Control Prevention. How tobacco smoke causes disease: the biology and behavioral basis for smoking-attributable disease: a report of the surgeon general. Atlanta: US Department of Health and Human Services, 2010.

23 Care AS, Bourque SL, Morton JS, Hjartarson EP, Davidge ST. Effect of advanced maternal age on pregnancy outcomes and vascular function in the rat. Hypertension 2015;65:1324-30.

24 Bray JK, Gorman DR, Dundas K, Sim J. Obstetric care of New European migrants in Scotland: an audit of antenatal care, obstetric outcomes and communication. Scott Med J 2010;55:26-31.

25 Bhatla N, Lal S, Behera G, Kriplani A, Mittal S, Agarwal N, et al. Cardiac disease in pregnancy. Int J Gynaecol Obstet 2003;82:153-9.

26 Liu S, Wen SW, Demissie K, Marcoux S, Kramer MS. Maternal asthma and pregnancy outcomes: a retrospective cohort study. Am J Obstet Gynecol 2001;184:90-6.

27 Aasheim V, Waldenstrom U, Hjelmstedt A, Rasmussen S, Pettersson $H$, Schytt E. Associations between advanced maternal age and psychological distress in primiparous women, from early pregnancy to 18 months postpartum. BJOG 2012;119:1108-16.

28 Montan S. Increased risk in the elderly parturient. Curr Opin Obstet Gynecol 2007;19:110-2.

29 Bramham K, Briley AL, Seed P, Poston L, Shennan AH, Chappell LC. Adverse maternal and perinatal outcomes in women with previous preeclampsia: a prospective study. Am J Obstet Gynecol 2011;204: 512.

30 Ford JB, Roberts CL, Bell JC, Algert CS, Morris JM. Postpartum haemorrhage occurrence and recurrence: a population-based study. Med J Aust 2007;187:391.

31 Johnson KA, Gee RE. Interpregnancy care. Semin Perinatol 2015;39: 310-5. 